\title{
EDGAR MORIN EN TRES TIEMPOS
}

Maria da Conceição de Almeida*

RESUMEN: Con base en fragmentos de conferencias, textos publicados en Brasil y una colaboración que será publicada próximamente en Estados Unidos, el artículo expone, de forma sintética, aspectos del perfil intelectual de Edgar Morin, su planteamiento de una reforma de la educación y su concepción de la investigación como "transformación social", que debe abrirse a la comprensión del desorden del mundo.

$$
\text { sose }
$$

ABSTRACT: Based on excerpts from conferences, published books in Brazil, and a collaboration that will soon be published in the United States, this article succinctly presents aspects of Edgar Morin's intellectual work, his proposal for reform in education and his idea of research as a social transformation allowing us to better understand chaos in the world.

PALABRAS ClAVE: Morin, método, educación, complejidad, Universidad, desorden.

KEYWORDS: Morin, method, education, complexity, University, chaos.

RECEPCIÓN: 24 de diciembre de 2009.

APROBACIÓN: 18 de enero de 2010.

* Antropóloga. Profesora del Programa del Posgrado en Educación y Ciencias Sociales de la Universidad Federal de Rio Grande do Norte. Coordinadora del Grupo de Estudios de la Complejidad-GRECOM. 
CITAM Derechos Reservados.

La reproducción total o parcial de este artículo se podrá hacer si el ITAM otorga la autorización previamente por escrito. 


\section{EDGAR MORIN EN TRES TIEMPOS*}

\section{Un pensador entero, híbrido y rebelde}

Edgar Morin es uno de los expositores más significativos del pensamiento mundial contemporáneo. Un hombre que desea y provoca, sin tregua, el reencuentro entre ciencia y humanismo, ética y conocimiento, vida e ideas. Un intelectual cuyas ideas constituyen una síntesis abierta, pero al mismo tiempo radical, del papel social del conocimiento ante la "agonía global" que caracteriza la época presente, en una escala planetaria.

Autor de una producción científica polémica, que ha conocido indiscutiblemente una repercusión y reconocimiento internacionales, Edgar Morin nace el 8 de julio de 1921, hijo de Vidal Nahum y de la bella Luna Beressi. Su obra no resulta fácil de clasificar en un área específica del conocimiento. Esa dificultad se presenta ya desde su nacimiento y surge desde su infancia. En una ocasión, alguien le pregunta al pequeño Edgar por su origen, $\mathrm{y}$, más concretamente, quiere saber de dónde era su padre: "De Salónica”, respondió Edgar. "Entonces, ¿es griego?”, le preguntaron. "No, porque Salónica era de Turquía cuando él nació." "Entonces, ¿es turco?” "No, su familia era española..." "Entonces, ¿es español?" "No...", trataba de explicar Edgar, a quien su padre le decía "Bebeco", y después "Minou”, y luego fue Edgar Nahum Morin, y

\footnotetext{
* Traducción de Blanca Luz Pulido.
} 
finalmente Edgar Morin, sobrenombre con el que lo conocían sus compañeros de la resistencia francesa. ${ }^{1}$

En los medios masivos de comunicación, así como en las diversas instituciones donde ha colaborado, es considerado como sociólogo, como filósofo, o incluso como antropólogo. Pero, ¿es posible atribuirle una cercanía exclusiva y unitaria a cualquiera de estos campos?

Licenciado en Historia, Geografía y Derecho, en realidad es, como él mismo ha dicho muchas veces, "un contrabandista de saberes", un "artesano sin patente registrada", porque se mueve libremente en medio de las divisiones arbitrarias entre las ciencias de la materia, de la vida y del hombre. Quiere volver a unir lo que el pensamiento fragmentado de la hiperespecialización disciplinaria separó. Lo impulsan varios daimones, pero una sola obsesión, un mismo impulso intelectual, una sola razón apasionada: la reforma del pensamiento. Morin nos alerta contra el peligro de las generalizaciones y, siguiendo la línea de Adorno y Gödel, reafirma que "la totalidad es la no verdad" y que la complejidad se caracteriza por una dinámica de la "incompletud".

Sin renunciar a la disciplina intelectual y al rigor, Edgar Morin se basa en la hipótesis de la tragedia del carácter inacabado de la cultura, del sujeto, de las ideas, del conocimiento. Por esa razón, las verdades absolutas y las explicaciones finalistas son rigurosamente cuestionadas y discutidas a lo largo de su obra abierta, que abarca desde una reflexión básica acerca del método, hasta textos que se encuentran en los terrenos de la sociología, la antropología, la política, los escritos de coyuntura, los libros autobiográficos, las novelas, el cine, la ficción y la cultura de masas.

Como el legendario Sísifo, Morin tomó a su cargo, valerosamente, la misión (¿o el castigo?) de hacer caer las piedras del conocimiento desde la cima de la montaña, con el objeto de unificar los saberes, aunque, como Sísifo, haya visto ya muchos despeñamientos.

Al contrario de los pensadores que, desencantados de la Universidad, optaron por aplicar fuera de ella sus energías cognitivas, el Sísifo Morin lucha contra el inmovilismo y la esclerosis del pensamiento dentro y

${ }^{1}$ Morin, Os meus demônios, 1995, Lisboa, Publicações Europa-América, p. 86. 
fuera de la academia. Su crítica incisiva y casi cruel a la "burocratización del saber" y a la "alta cretinización" que obstaculizan a la ciencia, es inseparable de su autocrítica que, en ocasiones demasiado rigurosa, lo ha obligado a enfrentar equívocos producidos por otros.

Debido a su polifonía temática y a la repercusión mundial de sus ideas, estamos frente a un pensador que hizo a un lado los cómodos límites entre las diferentes disciplinas, para lanzarse a la tarea incierta, aunque impostergable, de hacer dialogar los conocimientos entre sí, condición esencial para que enfrentemos los desafíos de todo tipo, ya seamos políticos, académicos o ciudadanos comunes. Pensador inclasificable y múltiple, es el eterno estudiante; en una ocasión fue definido por el periódico La libre Belgique como "un humanista sin fronteras". Un intelectual que politiza el conocimiento; un hombre para quien sólo puede existir la "ciencia con conciencia"; un pensador que expone abiertamente sus dudas, cree en la "buena utopía” y en la reforma de la Universidad y de la enseñanza elemental. Morin defiende públicamente sus posiciones ante los conflictos y las guerras y se somete a la democracia del debate para reconsiderar sus posiciones y argumentos, porque se opone abiertamente a la policía del pensamiento. Se trata, así, de un intelectual que sienta las bases de una ética planetaria, aquella que empieza por la ética individual: una autoética.

Edgar Morin no se esconde en las palabras, sino que se expone peligrosamente por medio de ellas, como practicante de lo que ha llamado la "autoética". Como sostiene en su libro Mis demonios: "ella me exige que no disimule la subjetividad en mis escritos, que no me erija en propietario de la verdad objetiva, que deje que el lector me vea, con todas mis debilidades y mezquindades, incluso corriendo el riesgo de dar a mis adversarios motivos para ridiculizarme". ${ }^{2}$ Un intelectual a quien incomoda el culto a la personalidad, aunque a veces sucumba ante él: "Hago un esfuerzo constante para no ponerme en un pedestal [...] porque la estatua exterior, la que se muestra a los demás, viene de la estatua interior, aquella que, inconscientemente, se esculpe para sí mismo". ${ }^{3}$

${ }^{2}$ Op. cit., p. 74.

${ }^{3}$ Ibidem. 
Ese enunciado no se limita a un juego de palabras, no es una simple figura retórica. Quien haya leído los libros: Diario de California, Vidal y los suyos, Diario de China, Mis demonios, Un año Sísifo, Llorar, amar, reír, comprender, conoce bien los conflictos intelectuales, las disputas teóricas, las alegrías, dolores, contratiempos, decepciones, lecturas y casualidades que han conformado su vida. En una palabra, conoce las situaciones de surgimiento y metamorfosis de los conceptos centrales y periféricos que utiliza Edgar Morin para reorganizar el conocimiento en "metaniveles" aún más complejos.

Esta situación nos indica una diferencia esencial en la comprensión y construcción de la historia de la ciencia. Leer el conjunto de El Método - libros con una gran densidad de conceptos, nociones y referencias a pensadores de diversas áreas del conocimiento-, contando con una visión de las condiciones psíquicas, sociales y políticas en las que se encuentra inmerso Morin, equivale a desacralizar la ciencia, facilitar la comprensión del lenguaje técnico y destruir la falacia del poder, del saber envuelto en el velo de la oscuridad y del secreto. Equivale, sobre todo, a reintroducir al sujeto en el conocimiento y al conocimiento en el sujeto, principio esencial para Morin.

Sin brújula que señale una dirección predefinida, este sabio moderno se convierte en el caminante del poeta Antonio Machado; rechaza la ortodoxia de cualquier signo y emprende una odisea del pensamiento. Como Ulises, algunas veces resulta herido en su travesía. Pero su cicatriz no está en la pierna, sino que se aloja en el fondo de su alma y vuelve a abrirse cada vez que asiste a las atrocidades provocadas por la tecnopolítica del pensamiento. Como el Ulises de Homero, que se viste de nativo cuando llega al país de los feacios, Morin sabe transitar con osadía por los diversos campos del conocimiento y, sobre todo, matizar la relación entre "amor, poesía y sabiduría".

Un sabio que abraza el exilio para ensayar un nuevo conocimiento del hombre en el universo. Un intelectual que critica las afiliaciones teóricas doctrinarias, abomina de los "gurús" y las "palabras clave", apuesta por una racionalidad que no se parece a ninguna forma de racionalización, que para él constituye una “patología”. Defiende una razón 
abierta y, más aún, un pensamiento y una teoría "biodegradables". Repite varias veces: "El único pensamiento vivo es el que conserva la temperatura de su propia destrucción".

Ecólogo de los ideales, transita por la biología, la física, la teoría de los sistemas y por otros campos del saber, para afirmar, por ejemplo, que como cualquier sistema autoorganizado, también el pensamiento y las interpretaciones, necesitan ser retroalimentados de forma constante por el mundo, por la realidad, que, además, no es verdaderamente tan real. Sin embargo, no reduce el conocimiento del hombre y del mundo al biologismo, al fisicismo o a cualquier otro campo de la ciencia. Defiende y pone en práctica la transdisciplinariedad, como la mirada que "teje en conjunto" la complejidad del mundo, del hombre, de la materia, de las luchas políticas. Renuncia, definitivamente, a la cómoda posición elitista y autoritaria que separa a la ciencia de la no ciencia. Llega a afirmar, en el tercer tomo de El Método que, a veces, hay más creación en una taberna popular que en un coctel literario. Afirmará, en una conferencia en Portugal, que el pensamiento complejo no debe reducirse al terreno académico, sino que debe llegar a las calles y a las plazas.

La crisis del mundo contemporáneo, la fragilidad democrática, la reorganización del conocimiento científico, además de sus posiciones políticas claras y valientes, forman parte de un planteamiento intelectual que nos invita a reflexionar más allá de las certezas arrogantes y de las verdades totalitarias y dementes.

Con un enfoque completamente opuesto a las posiciones relativistas y esquizofrénicas, que oponen lo público a lo privado, Morin confiesa que le gusta mezclar vida e ideas. "Puse mi vida en las ideas y las ideas en mi vida", ha afirmado en varias ocasiones.

Este pensador, generoso con sus ideas, sabe como ningún otro usar una sutil ironía cuando lo provocan los cartesianos rígidos. Imágenes como las de "burócratas del saber", aguda, media y baja "cretinización" del conocimiento y de la academia, además de otras frases aún más duras, se transforman en metáforas dentro de su obra y hacen de sus libros una literatura científica abierta a la vida, nunca textos soporíferos ni pacificadores. 
Todo lo que hasta aquí hemos dicho constituye, en verdad, un perfil incompleto de un pensador siempre cambiante que nos invita a vivir en la incertidumbre; que sabe mostrar el carácter siempre incompleto y parcial del conocimiento; que instiga la curiosidad y previene contra el peligro del placer autocentrado del saber; que nos invita a abandonar cualquier forma de arrogancia científica.

\section{Un pensador de la educación}

Consciente de que la construcción de una sociedad más justa e igualiaria sólo es posible mediante una nueva y compleja comprensión del mundo, Morin ha apostado, desde fines de la década de 1990, por la reforma del sistema educativo. Los libros Los siete saberes necesarios para una educación del futuro, La cabeza bien puesta y La religación de los conocimientos muestran su gran interés en la educación.

En 1997, invitado a Francia por Claude Allégre, quien era en esos años ministro de Educación, para asumir la presidencia de un consejo científico encargado de hacer la reforma de la enseñanza secundaria, Morin confiesa no haber visto realizarse la transformación que soñó, encaminada a lograr una formación más integral del ciudadano. Hubo resistencias de varios tipos: sindical, burocrática, la remanente del poder disciplinario, pero ninguna de ellas disminuyó su interés por la defensa de una educación abocada a la complejidad. El libro La religación de los conocimientos ${ }^{4}$ expone el proyecto conocido como "Jornadas temáticas", dividido en ocho temas: 1. El mundo; 2. La Tierra; 3. La vida; 4. La humanidad; 5. Las lenguas, civilizaciones, literatura, artes y cine; 6. La historia; 7. La cultura de los adolescentes, y, 8. La religación de los conocimientos. En aquella ocasión, físicos, matemáticos, biólogos, filósofos e investigadores de otras áreas del conocimiento expusieron sus conceptos, teorías e interpretaciones dirigidas a fundamentar una ecología del conocimiento para instaurar una "enseñanza-educación" en las escuelas. El objetivo de largo alcance, diseñado por Morin

${ }^{4}$ A religação dos saberes - O desafio do século XXI, 2001, Río de Janeiro, Bertrand Brasil. 
a partir de esas jornadas, era sentar las bases para la construcción de un "conocimiento pertinente", es decir, un conocimiento "capaz de situar cualquier información en su contexto y, si es posible, en el campo general en el que está inscrita". ${ }^{5}$ Más allá de una transformación burocrática de las estructuras escolares, existe una apuesta mayor: estimular la autoenseñanza, despertando, provocando, favoreciendo la autonomía del espíritu". ${ }^{6}$

Aunque la reforma de la enseñanza francesa haya sido tímida en relación con la osada proposición de Edgar Morin, sus ideas y metaprincipios sirven hoy de base para reformar la enseñanza en escuelas y universidades de diversos países.

En el contexto de los proyectos relativos a la reforma de la educación, es importante no perder de vista algunas de los metaproblemas planteados por Morin, a quien se considera como el protagonista central de la reforma del pensamiento. Hay tres metaproblemas en los que hay que reflexionar, en el terreno de la enseñanza superior universitaria: 1. La reforma de la Universidad no debe reducirse a una reforma pragmática, ya que implica una reforma paradigmática. Los otros dos problemas se formulan como preguntas: 2. ¿Debe la Universidad adaptarse a la sociedad, o la sociedad a la Universidad? 3. ¿De dónde partirán o deberían partir las propuestas de reforma? Morin, ante esta última pregunta, considera que, si bien es necesario transformar la estructura hegemónica de la academia, es importante tomar en cuenta las iniciativas marginales. Afirma, en La cabeza bien puesta: "Podríamos imaginar también que en cada universidad podría crearse un centro de investigaciones sobre los problemas de la complejidad y de la transdisciplinariedad, así como talleres o seminarios sobre las problemáticas complejas y trandisciplinarias". ?

En síntesis, para plantearnos el tema de los conocimientos necesarios para la educación del futuro, es fundamental establecer una agenda de principios múltiples: 1. Pensar en la educación como una actividad humana llena de incertidumbre e indeterminación, pero también compro-

${ }^{5}$ Op. cit., p. 15.

${ }^{6}$ Idem, p. 11.

${ }^{7}$ A cabeça bem-feita, 2000, Río de Janeiro, Bertrand Brasil, p. 85. 
metida con los destinos de los hombres, las mujeres y los niños que habitan nuestra "Tierra Patria"; 2. Practicar una ética del conocimiento que implique un pacto con el presente, sin olvidar nuestro compromiso con el futuro; 3. Buscar las conexiones existentes entre el fenómeno que queremos comprender y el contexto en que se inscribe; 4 . Renunciar a la ortodoxia, a las respuestas fáciles, finalistas y completas; 5. Ejercitar el diálogo entre los diferentes dominios de las especialidades; 6. Favorecer el surgimiento de la complementariedad entre arte, ciencia y literatura; 7. Transformar nuestras enseñanzas en lenguajes que amplíen el número de interlocutores de la ciencia.

Es posible que los siete puntos de ese programa abierto sirvan de contexto para lo que Edgar Morin denomina Los siete saberes necesarios para una educación del futuro: aprender del error y la ilusión; construir un conocimiento pertinente; enseñar la comprensión humana; enseñar la identidad humana; enfrentar las incertidumbres; enseñar la comprensión y ejercitar la ética de lo humano. ${ }^{8}$

\section{Investigador del desorden}

18 Edgar Morin marca el inicio de una nueva concepción de todo lo que es investigación y método científico de investigación. Su nueva concepción se relaciona con el deseo de cuestionar el deseo de orden, verdadera obsesión del paradigma cartesiano.

El deseo de instaurar un orden en el caos, tan importante en el discurso tanto narrativo como mítico y científico, se ha convertido a veces en un sentimiento de orden. Esa transformación del deseo en sentimiento ocurre de forma análoga a lo que sucede con la idea de verdad cuando se transforma en un sentimiento de verdad, señala Edgar Morin en su Método III. ${ }^{9}$ Así, durante la consolidación de las ciencias modernas -nacidas en el siglo XVII- se crea una obsesión por la búsqueda del orden como un principio irrenunciable del sujeto cognoscente. Este orden,

${ }^{8}$ Os sete saberes necessários à educação do futuro, 2000, São Paulo, Cortez; Brasilia UNESCO.

${ }^{9}$ O Método III: O conhecimento do conhecimento, 1999, Porto Alegre, Sulina, p. 160-2. 
que no se percibe como una construcción del pensamiento, se consideró como algo evidente, dando a los científicos "una paz profunda, una alegría infinita", en palabras de Morin. Para él, "en Descartes, la evidencia nace del acuerdo establecido entre el orden del Espíritu (las ideas claras y distintas) y el orden del universo"; incluso podría ser que, en la base de todo conocimiento intelectual, la armonía que parece establecerse por una "adecuación entre el intelecto y la cosa" (definición clásica de la verdad) comportara el "sentimiento de evidencia". ${ }^{10}$

Para Morin, gracias al desarrollo de la ciencia, "el concepto de orden se relativizó. La complejización y la relativización van de la mano. Ya no existe un orden absoluto, incondicional, eterno". ${ }^{11} \mathrm{Y}$ en cuanto al desorden, también se transformó y va más allá de la contingencia del azar, aunque lo implique. "Puedo afirmar incluso que la idea del desorden es más completa que la idea del orden, porque implica necesariamente un polo objetivo y un polo subjetivo. En el polo objetivo se manifiesta en agitación, dispersión, irregularidades, inestabilidades, perturbaciones, encuentros azarosos, accidentes, desorganizaciones, ruidos y errores". ${ }^{12}$ En el polo subjetivo, se manifiesta en la condición de indeterminación e incertidumbre, propios de los sistemas complejos y del espíritu humano.

Así pues, no es posible concebir el orden sin el desorden, ni el desorden sin el orden. Un universo constituido sólo por el orden sería un universo sin porvenir, innovación ni creación. Del mismo modo, un universo que sólo fuera desorden no lograría organizarse, y por lo tanto, sería incapaz de preservar las novedades -señala Morin-, de evolucionar y desarrollarse.

Esa referencia a la dialógica que constituye la pareja orden-desorden inaugura el camino para la construcción del tetragrama ordendesorden-interacción-organización, operador cognitivo importante del método complejo diseñado por Morin. Ese tetragrama, lejos de prefigurar un modelo pragmático para la construcción del conocimiento mediante la investigación, necesita y depende de un sujeto capaz de compren-

${ }^{10} \mathrm{Op}$. cit., p. 162.

${ }^{11}$ Ciência com consciência, 1982, Lisboa, Publicações Europa-América, p. 73.

${ }^{12}$ Idem., p. 74. 
der y poner en práctica la dialógica entre organización y ambiente, objeto y sujeto. Desde el punto de vista de las ciencias de la complejidad, estamos ante una reconsideración de la naturaleza del campo del conocimiento. "El campo real del conocimiento no es el objeto puro, sino el objeto visto, percibido y coproducido por nosotros mismos. Esa fenomenología es nuestra realidad como seres en el mundo. Las observaciones hechas por espíritus humanos conllevan la presencia inevitable del orden, el desorden y la organización en los fenómenos microfísicos, macrofísicos, astrofísicos, biológicos, ecológicos, antropológicos, etc. Nuestro mundo real es el de un universo del cual el observador nunca podrá suprimir los desórdenes, y del cual no se podrá suprimir a sí mismo". ${ }^{13}$

Para Morin, si a partir de esas ideas no es posible inferir una lección directa ni una receta pragmática, "hay en ellas, sin embargo, una invitación directa a romper con la mitología o la ideología del orden. La mitología del orden no reside sólo en la idea reaccionaria según la cual toda innovación, toda novedad implica decadencia, peligro y muerte, sino también en la utopía de una sociedad transparente, sin conflictos y sin desorden". ${ }^{14}$

La perspectiva de la cual Morin difiere sustancialmente, es la que postula "una sociología dominante que reduce la sociedad a la sola noción de sociedad postindustrial, circunscribe lo singular concreto en monografías descriptivas y elimina pura y simplemente lo ocasional, considerándolo como accidente, como una contingencia que debe ser descartada para concebir la verdadera realidad social, que tiende a la repetición, a la regularidad, o sea, a la estructura". ${ }^{15}$

Lo ocasional, en el sentido de acontecimiento o fenómeno esporádico y no regular, según Morin tiene una importancia crucial para abordar el proceso del cambio social. Lo ocasional, lo singular, es una "prueba activa" sobre el sistema sobre el que actúa, al mismo tiempo que interviene de manera múltiple y decisiva en la historia humana. "Lo que es excluido como insignificante, imponderable o estadísticamente minoritario; lo que perturba la estructura o el sistema, todo eso es para nosotros

${ }^{13}$ Idem, p. 78.

${ }^{14}$ Idem, p. 79.

${ }^{15}$ Morin, Sociología, 1995, Madrid, Editorial Tecnos, p. 186. 
altamente significativo y revelador; es una enzima aceleradora, un fermento, un virus, un detonador, un agente modificador". ${ }^{16}$

Utilizando la literatura, estrategia narrativa habitual en toda su obra, Morin emplea hermosas imágenes para hablar del investigador y de las investigaciones; para él, es necesario que a veces actuemos como Balzac (descripción enciclopédica de la realidad), y a veces como Stendhal (observar el "detalle significativo"). En ese panorama, pierde sentido la oposición entre micro y macroinvestigación. Morin se pregunta si es una paradoja afirmar que, cuanto más particular es un estudio, ¡más general debe ser!

Próxima a una ciencia de lo sensible, la actitud fenomenológica expone el horizonte de las investigaciones basadas en el pensamiento complejo. "Se trata, por lo tanto, de proporcionar - a partir de un impulso fenomenológico- un sustento a la teoría y a lo concreto, ambos correlativamente atrofiados, subdesarollados, asfixiados en un 'término medio' entre la teoría y lo concreto, pobre una y mutilado el otro". ${ }^{17}$

Um método vivo, en permanente reconstrucción, capaz de articular objetividad y subjetividad. Principios generales que requieren creatividad, sensibilidad e iniciativa de parte del investigador, y que, al mismo tiempo, permiten distinguir entre la rigidez y el rigor científico. Ésa puede ser una síntesis provisional sobre el desafío del método complejo en la investigación. Más aún: lejos del divorcio entre teoría y práctica, investigación básica e investigación aplicada -divisiones tan apreciadas por los departamentos de fomento a la investigación-, lo importante sería escuchar una vez más a Morin: "cuanto más empírica es la investigación, más reflexiva debe ser". ${ }^{18}$ 
CITAM Derechos Reservados.

La reproducción total o parcial de este artículo se podrá hacer si el ITAM otorga la autorización previamente por escrito. 